\title{
Tumores testiculares bilaterales: experiencia de 25 años en un hospital de tercer nivel de la Ciudad de México
}

Ortega-González ME, ${ }^{1}$ Hernández-Méndez $\mathrm{E},{ }^{1}$ Cortes-Raygoza $\mathrm{P},{ }^{1}$ CalvoVázquez I, ${ }^{1}$ Veliz-Cabrera $\mathrm{G},{ }^{1}$ López-Maguey $\mathrm{R},{ }^{1}$ y colaboradores.

\section{Resumen}

ANTECEDENTES: el cáncer de testículo representa el proceso maligno más frecuente en varones de 15 a 35 años de edad. El antecedente de tumor testicular germinal es el principal factor de riesgo para padecer cáncer testicular contralateral.

OBJETIVO: describir las características clínicas e histopatológicas de los pacientes con tumores testiculares bilaterales sincrónicos y metacrónicos.

MATERIALES Y MÉTODOS: estudio retrospectivo, descriptivo, transversal, realizado en pacientes con diagnóstico de tumor testicular, atendidos en la División de Urología del Hospital General Dr. Manuel Gea González, entre enero de 1989 a enero de 2016. Se evaluaron las características demográficas, clínicas e histopatológicas, con la finalidad de efectuar el análisis descriptivo.

RESULTADOS: se incluyeron 346 pacientes con cáncer de testículo, de los que solo se identificaron 9 (2.6\%) casos con tumores bilaterales, con edad promedio de 40.2 años: 7 (77.7\%) de manifestación sincrónica y $2(22.2 \%)$ metacrónica. El resultado histopatológico más frecuente fue seminoma clásico $(n=5 ; 55.5 \%)$, linfoma ( $n$ $=2 ; 22.2 \%)$, tumor germinal mixto $(\mathrm{n}=1 ; 11.1 \%)$ y seminoma espermatocítico $(\mathrm{n}=1 ; 11.1 \%)$. El tratamiento consistió en orquiectomía radical bilateral $(\mathrm{n}=9 ; 100 \%)$; terapia neoadyuvante con quimioterapia ( $\mathrm{n}=8 ; 88.8 \%$ ) y tratamiento hormonal androgénico ( $\mathrm{n}=6 ; 66.6 \%)$.

CONCLUSIÓN: Ios tumores testiculares bilaterales son poco frecuentes. El diagnóstico implica la participación de un equipo multidisciplinario (urólogo-oncólogo). Independientemente de la bilateralidad, el pronóstico depende del tipo histológico y estadificación tumoral, que en la mayoría de los casos supone alto porcentaje de curación.

PALABRAS CLAVE: tumores testiculares bilaterales, tumores sincrónicos, tumores metacrónicos.

\footnotetext{
${ }^{1}$ Residente de la División de Urología.

${ }^{2}$ Adscrito a la División de Urología.

${ }^{3}$ Residente de la División de Patología.

${ }^{4}$ Adscrito a la División de Patología.

${ }^{5}$ Jefe de la División de Patología.

${ }^{6}$ Jefe de la División de Urología.

Hospital General Dr. Manuel Gea González, Ciudad de México.
}

Recibido: diciembre 2016

Aceptado: julio 2017

Correspondencia

Dr. Mario Enrique Ortega González

meog_maranello@hotmail.com

Este artículo debe citarse como

Ortega-González ME, Hernández-Méndez E, Cortes-Raygoza P, Calvo-Vázquez I, Veliz-Cabrera G, López-Maguey $\mathrm{R}$, y col. Tumores testiculares bilaterales: experiencia de 25 años en un hospital de tercer nivel de la Ciudad de México. Rev Mex Urol. 2017 sep;77(5):353-360. DOI: https://doi.org/10.24245/revmexurol.v77i5.1113 
Rev Mex Urol. 2017 Sep-Oct;77(5):353-360.

\section{Bilateral testicular tumors: Twenty-five years of experience at a tertiary care hospital in Mexico City}

Ortega-González ME, ${ }^{1}$ Hernández-Méndez $\mathrm{E},{ }^{1}$ Cortes-Raygoza $\mathrm{P},{ }^{1}$ CalvoVázquez I, ${ }^{1}$ Veliz-Cabrera G, ${ }^{1}$ López-Maguey $R,{ }^{1}$ y colaboradores.

\begin{abstract}
BACKGROUND: Testicular cancer is the most frequent malignant process in males between 15 and 35 years of age. A history of germ cell testicular tumor is the main risk factor for presenting with contralateral testicular cancer.
\end{abstract}

AIM: To describe the clinical and histopathologic characteristics of patients with synchronous or metachronous bilateral testicular tumors.

MATERIALS AND METHODS: A retrospective, descriptive, crosssectional study was conducted on patients diagnosed with testicular tumor, seen at the Urology Division of the Hospital General "Dr. Manuel Gea González" within the time frame of January 1989 and January 2016. The demographic, clinical, and histopathologic characteristics of those patients were evaluated through a descriptive analysis.

RESULTS: The study included 346 patients with testicular cancer, 9 $(2.6 \%)$ of whom presented with bilateral tumors and had a mean age of 40.2 years: $7(77.7 \%)$ of those patients had synchronous tumors and $2(22.2 \%)$ had metachronous tumors. The reported histopathologic types were classic seminoma in $5(55.5 \%)$ patients, lymphoma in $2(22.2 \%)$ patients, mixed germ cell in $1(11.1 \%)$ patient, and spermatocytic seminoma in $1(11.1 \%)$ patient. All 9 patients $(100 \%)$ underwent bilateral orchiectomy, $8(88.8 \%)$ of the patients had neoadjuvant treatment with chemotherapy, and $6(66.6 \%)$ of the patients accepted hormone therapy.

CONCLUSIONS: Bilateral testicular tumors are rare. Once the diagnosis is made, management should be multidisciplinary (urologist/ oncologist). Regardless of bilaterality, outcome depends on tumor type and stage. The cure rate is high in the majority of cases.

KEYWORDS: Bilateral testicular tumor; Synchronous tumor; Metachronous tumor

\footnotetext{
${ }^{1}$ Residente de la División de Urología.

${ }^{2}$ Adscrito a la División de Urología.

${ }^{3}$ Residente de la División de Patología.

${ }^{4}$ Adscrito a la División de Patología.

${ }^{5}$ Jefe de la División de Patología.

${ }^{6}$ Jefe de la División de Urología.

Hospital General Dr. Manuel Gea González, Ciudad de México.
}

Correspondence

Dr. Mario Enrique Ortega González meog_maranello@hotmail.com

\section{ANTECEDENTES}

El cáncer de testículo representa el proceso maligno más frecuente en varones de 15 a 35 años de edad; supone $1 \%$ de todas las neoplasias urogenitales, incluso el tumor con la mayor tasa de curación. El riesgo de padecer un tumor testicular varía de 0.3 a $0.7 \%$, de acuerdo con 
la raza y localización geográfica. ${ }^{1}$ En Estados Unidos se diagnosticaron 7920 nuevos casos de cáncer testicular durante 2007, con índice de mortalidad de 390. ${ }^{2}$ En México, su incidencia se sitúa entre 0.5 y 1.9 casos por cada 100,000 habitantes al año, con edad media al momento del diagnóstico de 34 y mediana de 39.5 años. ${ }^{3}$

La incidencia de cáncer testicular se ha incrementado en las últimas tres décadas, probablemente por el aumento de la supervivencia, además de diversos factores de riesgo como: antecedentes familiares, criptorquidia, disgenesia gonadal, infertilidad, atrofia testicular y traumatismo escrotal. El antecedente de tumor testicular germinal es el principal factor para padecer cáncer testicular contralateral. ${ }^{4}$

La neoplasia intraepitelial testicular y el carcinoma in situ, también conocido como neoplasia germinal intratubular, se han descrito como lesiones premalignas relacionadas con el origen de tumores testiculares unilaterales o bilaterales. ${ }^{5}$

Si se excluyeran las neoplasias secundarias, metastásicas y hematológicas, la prevalencia del tumor germinal de testículo bilateral se situaría entre 1 y $4 \% .{ }^{6}$ El primer caso de tumor testicular bilateral fue reportado por Livingstone en $1854 .^{7}$

Hasta el momento no existe un consenso del tiempo estimado para definir la metacronicidad; sin embargo, este subtipo aparece en más de $75 \%$ de los casos, con un promedio de hasta 5 años de intervalo, según las mayores series publicadas, incluso se sugiere que $23 \%$ de los pacientes puede manifestar un tumor metacrónico después de 10 años del diagnóstico inicial. ${ }^{8}$ La incidencia de cáncer testicular bilateral varía según diferentes estudios, por ejemplo: $1 \%$ en la serie del MD Anderson Cancer Center, 1.2\% en el Memorial Sloan Kettering Cancer Center y $1.9 \%$ en el Institute Gustave Roussy. ${ }^{9}$
El riesgo de manifestar un segundo tumor germinal en un paciente con antecedente de neoplasia testicular es mayor al de la población general. ${ }^{10}$ Cuando los tumores son sincrónicos, expresan características histológicas idénticas en ambos testículos y es mucho más frecuente la manifestación de tumores seminomatosos que los no seminomatosos, probablemente por recibir el mismo estímulo carcinogénico y por la falta de diferenciación celular hacia alguna de las líneas específicas. ${ }^{11}$

El objetivo del presente trabajo es: describir las características clínicas e histopatológicas de los pacientes con tumores testiculares bilaterales sincrónicos y metacrónicos.

\section{MATERIALES Y MÉTODOS}

Estudio retrospectivo, descriptivo y transversal, realizado en pacientes con diagnóstico de tumor testicular que acudieron a la División de Urología del Hospital General Dr. Manuel Gea González, entre enero de 1989 y enero 2016. Se evaluaron las características demográficas, clínicas e histopatológicas, con la finalidad de efectuar el análisis descriptivo.

\section{RESULTADOS}

Se incluyeron 346 pacientes con diagnóstico de cáncer testicular; sin embargo, solo en 9 (2.6\%) se identificaron tumores bilaterales (Figuras $\mathbf{1}$ y 2). La edad promedio de manifestación fue de 40.2 años (límites de 20 a 85), principalmente la forma sincrónica en 7 (77.7\%) casos y metacrónica en 2 (22.2\%).

El tipo histopatológico más frecuente fue seminoma clásico (Figura 3) en 5 (55.5\%) pacientes, seguido de linfoma en $2(22.2 \%)$, germinal mixto en $1(11.1 \%)$ Figuras 4 y $\mathbf{5}$, y seminoma espermatocítico en $1(11.1 \%)$. Figuras 6 y 7 


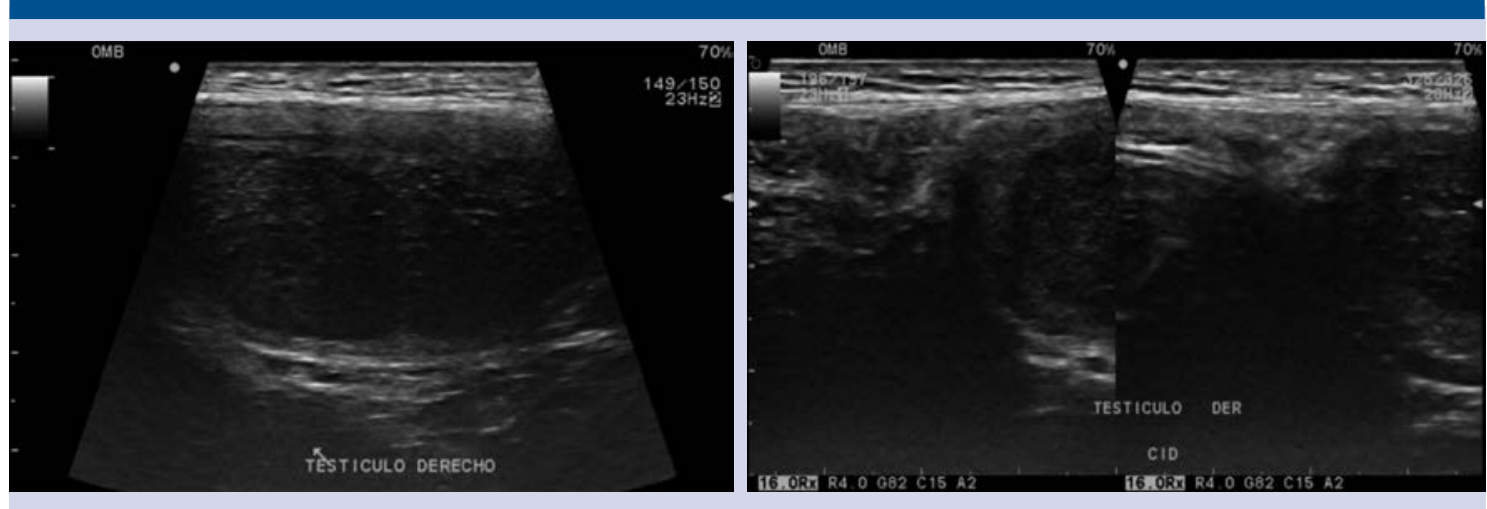

Figura 1. Ultrasonido que muestra un tumor espermatocítico en el testículo derecho.
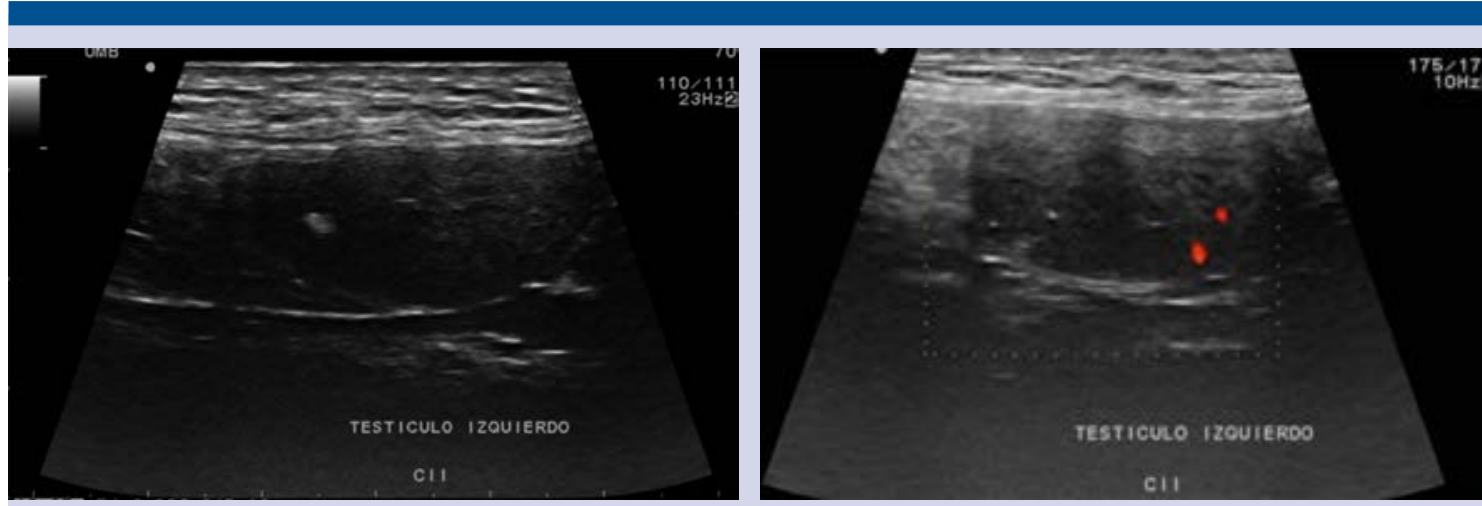

Figura 2. Identificación de un tumor sincrónico espermatocítico en el testículo izquierdo.

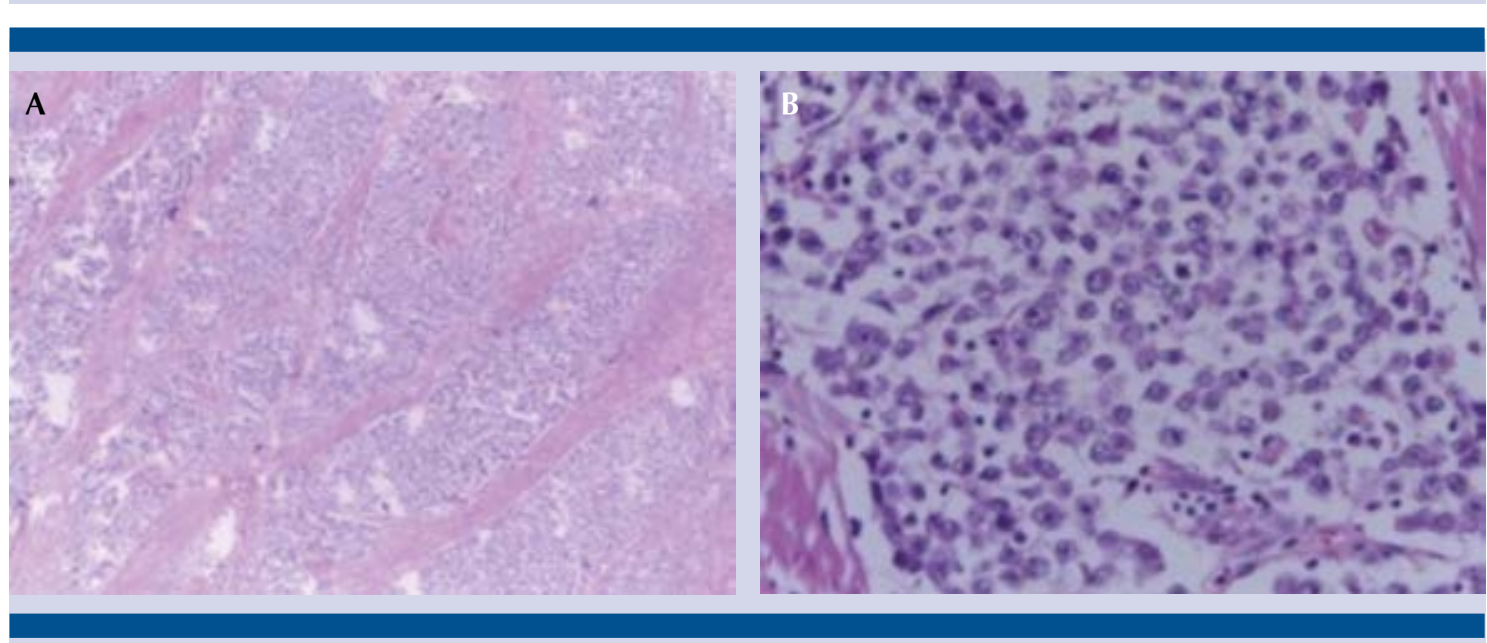

Figura 3. Corte histológico (H-E) de un seminoma testicular a 4x (A) y 40x (B). 


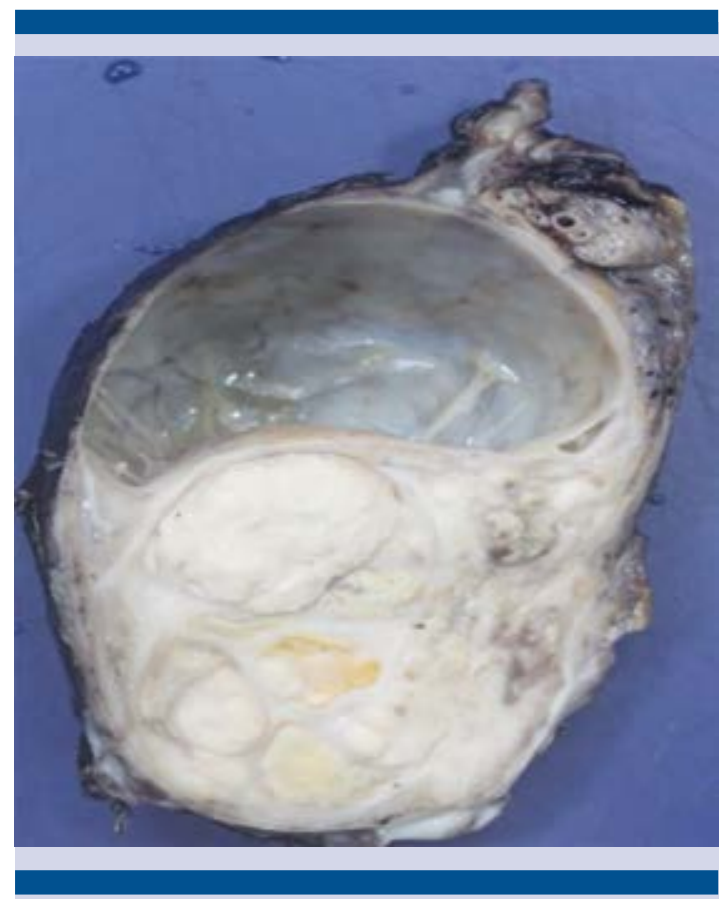

Figura 4. Tumor germinal mixto.

En todos los pacientes $(\mathrm{n}=9$ ) se practicó orquiectomía radical bilateral; 7 (88.8\%) casos recibieron tratamiento neoadyuvante con quimioterapia, mediante el esquema BEP (etopósido, cisplatino, bleomicina) para tumores no hematológicos. Se decidió prescribir tratamiento hormonal androgénico a todos los pacientes; sin embargo, solo 6 lo aceptaron (Cuadro 1). En relación con los factores de riesgo, se identificaron $2(22.2 \%)$ pacientes con tumoración testicular previa, $1(11.1 \%)$ con antecedente de criptorquidia bilateral y $1(11.1 \%)$ con síndrome genético (trisomía 21).

\section{DISCUSIÓN}

Los pacientes con tumores testiculares suelen tener buena evolución y pronóstico, incluso quienes padecen enfermedad avanzada. Respecto de los tumores bilaterales ( 0.8 cada 1,000,000 de varones entre 15 y 40 años de edad), son pocos los casos detectados con esta variante. Diversos estudios describen tumores bilaterales sincrónicos seminomatosos en la mayoría de los pacientes y con menor frecuencia tumores no seminomatosos (menos de $30 \%$ de los casos), lo que coincide con los resultados de nuestra serie. ${ }^{9}$

Los tumores testiculares bilaterales aparecen en 0.5 a $7 \%$ de los pacientes ${ }^{16}$ y su incidencia se ha incrementado en las últimas décadas. Entre

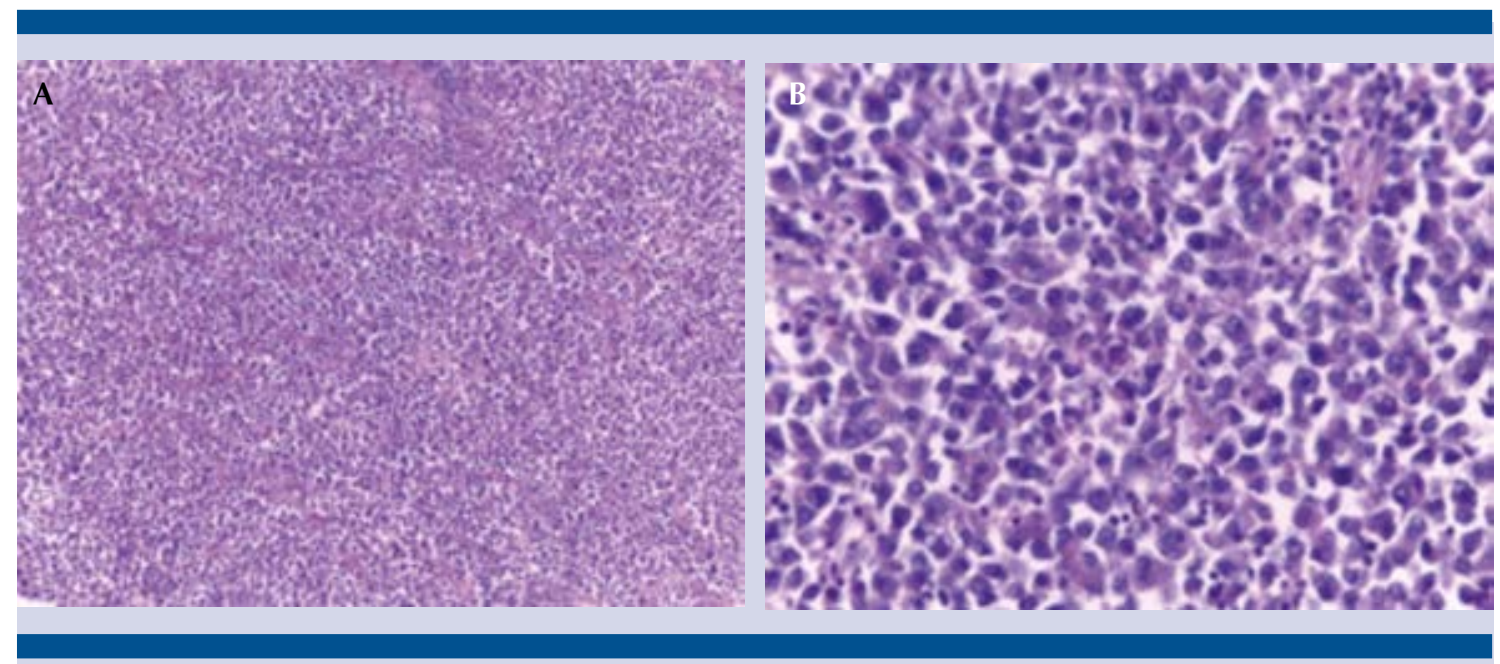

Figura 5. Corte histológico (H-E) de carcinoma germinal mixto a 4x (A) y 40x (B). 


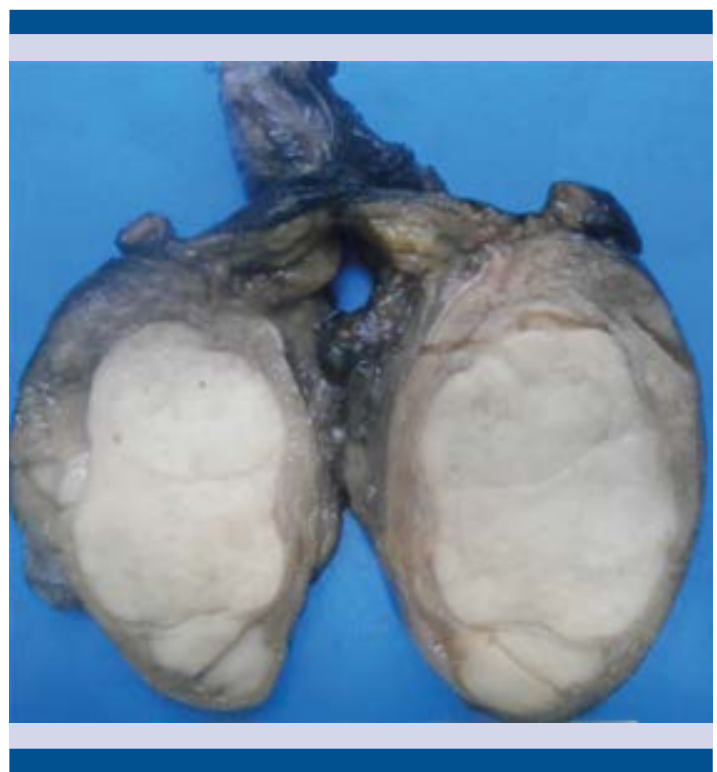

Figura 6. Seminoma espermatocítico.

los factores asociados con bilateralidad se encuentran: criptorquidia, antecedentes familiares y riesgo elevado de neoplasia previa; en nuestra serie se observó un comportamiento similar al reportado en la bibliografía. Klatte y sus colaboradores ${ }^{10}$ encontraron que el riesgo de manifestar un tumor testicular después de haber padecido cáncer de testículo de células germinales unilateral es 26 veces más alto que en la población sana. Aún se discute el tipo histológico y riesgo adicional en estos pacientes; algunos autores reportan riesgo elevado después de padecer un tumor de células germinales seminomatoso, ${ }^{11}$ otros señalan que existe mayor riesgo con tumores de células germinales no seminomatoso, incluso hay quienes señalan no encontrar relación. ${ }^{12}$

También se debate la obtención de biopsia contralateral al momento de la orquiectomía, con la finalidad de descartar una neoplasia intratubular (NIT), que representa un potencial precursor tumoral, puesto que son bajas las incidencias de NIT y de metacronicidad, además de la morbilidad del tratamiento con radioterapia local (infertilidad y alteraciones en la producción de testosterona); sin embargo, este tipo de biopsia debe indicarse y advertir a los pacientes con volumen testicular menor de $12 \mathrm{~mL}$, antecedente de criptorquidia y sujetos menores de 30 años de edad..$^{13}$

El seminoma es el tumor testicular contralateral más frecuente encontrado y suele relacionarse con la edad de manifestación del primer tumor. El seminoma es común en pacientes mayores de
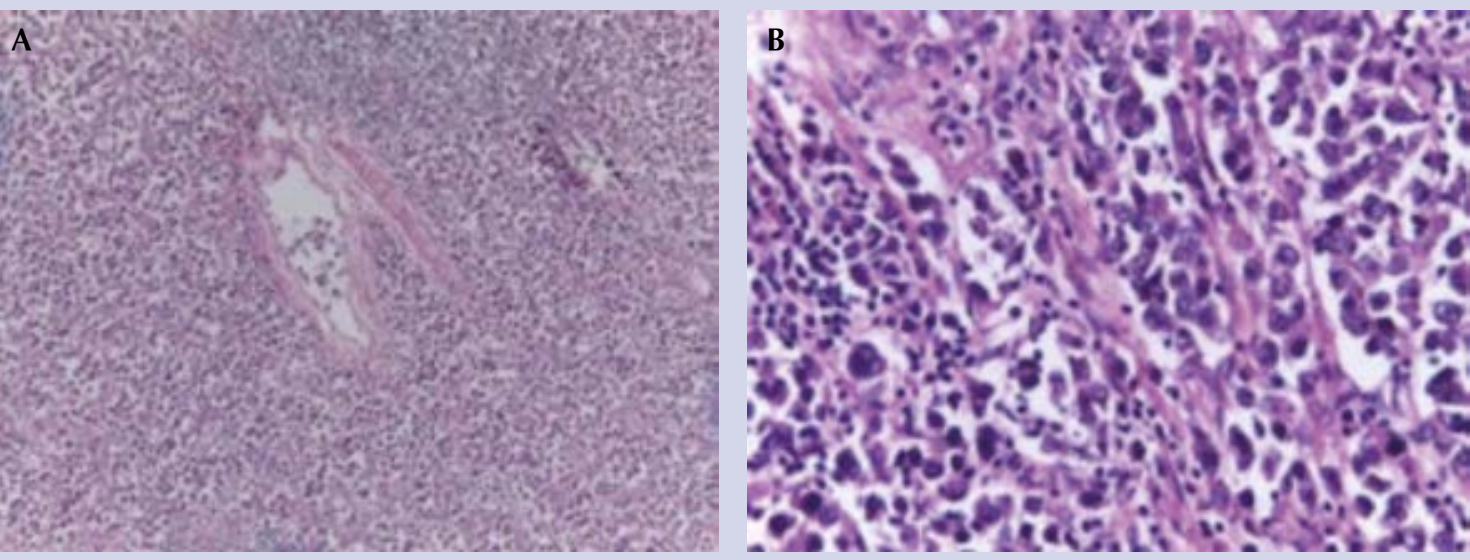

Figura 7. Corte histológico (H-E) de seminoma espermatocítico a 4x (A) y 40x (B). 
Cuadro 1. Características clínico-patológicas

\begin{tabular}{|l|c|c|c|c|c|c|c|}
\hline Caso & Edad & Presentación & Tipo histopatológico & TNM & Tx & Neoadyuvancia & $\begin{array}{c}\text { Tratamiento } \\
\text { hormonal }\end{array}$ \\
\hline 1 & 77 & Sincrónico & Seminoma clásico & pT1 N0 M0 S0 & ORB & BEP & Sí \\
\hline 2 & 34 & Sincrónico & Seminoma clásico & pT1 N0 M0 S0 & ORB & BEP & Sí \\
\hline 3 & 25 & Sincrónico & Seminoma clásico & pT1 N0 M0 S0 & ORB & NO & No \\
\hline 4 & 29 & Sincrónico & Seminoma clásico & PT1 N1 M0 S0 & ORB & BEP & Sí \\
\hline 5 & 31 & Metacrónico & Germinal mixto & pT1 N0 M0 S0 & ORB & BEP & Sí \\
\hline 6 & 29 & Sincrónico & Seminoma espermatocítico & pT1 N0 M0 S0 & ORB & BEP & Sí \\
\hline 7 & 20 & Metacrónico & Seminoma clásico & pT1 N0 M0 S0 & ORB & BEP & Sí \\
\hline 8 & 85 & Sincrónico & Linfoma & pT1 N0 M0 S0 & ORB & CHOP & No \\
\hline 9 & 45 & Sincrónico & Linfoma & pT1 N0 M0 S0 & ORB & R-CHOP & No \\
\hline
\end{tabular}

Tx: tratamiento quirúrgico; ORB: orquiectomía radical bilateral; BEP: etopósido, cisplatino, bleomicina; CHOP: ciclofosfamida, doxorrubicina, vincristina, prednisona; R-CHOP: rituximab, ciclofosfamida, doxorrubicina, vincristina, prednisona.

30 años de edad, como sucedió en los casos de nuestro estudio. Fossa y su grupo ${ }^{14}$ reportaron, en su estudio basado en los registros de cáncer de pacientes que participaron en el programa de Vigilancia, Epidemiología, y Resultados Finales (SEER, por sus siglas en inglés), efectuado entre 1973 y 2001, que de 29,515 hombres con cáncer testicular, 175 (5.9\%) correspondieron a tumor testicular sincrónico contralateral y 287 $(9.7 \%)$ a tumor metacrónico contralateral, en un promedio de 63 meses (5 años y 3 meses), datos similares al estudio aquí realizado.

El tratamiento de pacientes con tumores testiculares bilaterales o unilaterales depende de la histología y el grado de metástasis. El tratamiento de elección consiste en orquiectomía bilateral, con subsiguiente indicación de terapia hormonal de reemplazo de por vida, además de tratamiento oncológico en función del estadio clínico y, si se requiere, terapia coadyuvante. Todo ello sin contar con las alteraciones estéticas, que en la mayoría de los casos requiere prótesis.

\section{CONCLUSIONES}

Los pacientes con diagnóstico de tumor unilateral requieren vigilancia del testículo contralateral a largo plazo. Se recomienda programar citas de control, y efectuar exámenes y determinación de marcadores tumorales cada 2 meses durante el primer año, cada tres meses durante el segundo, cada 6 meses durante el tercer y cuarto año, y anualmente a partir del quinto año; así mismo, debe solicitarse tomografía abdominal simple cada 3-6 meses, con radiografía de tórax cada 2 meses durante el primer año, cada 3 meses durante el segundo y anualmente desde el tercer al quinto año.

Después de establecer el diagnóstico es importante el tratamiento multidisciplinario; independientemente de la bilateralidad, el pronóstico de los pacientes depende del tipo histológico y estadificación tumoral, que en la mayoría de los casos se ha observado alto porcentaje de curación.

\section{REFERENCIAS}

1. Che M, Tamboli P, Ro JY, Park Ds, et al. Bilateral testicular germ cell tumors: twenty-year experience at M. D. Anderson Cancer Center. Cancer 2014;95:1228-33.

2. Reinberg Y, Manivel JC, Zhang G, Reddy PK. Synchronous bilateral testicular germ cell tumors of different histologic type. Pathogenetic and practical implications of bilaterality in testicular germ cell tumors. Cancer 2016;681:1082-1085. 
3. Patel SR, Rachardson RL, Kvols L. Synchronous and metachronous bilateral testicular tumors. Mayo Clinic Experience. Cancer 2014;65:I-4.

4. Hentrich M, Weber N, Bergsdorf T, Liedi B, et al. Management and outcome of bilateral testicular germ cell tumors: Twenty-five year experience in Munich. Acta Oncol. 2015;44:529-536.

5. Holzbeierlein JM, Sogani PC, Sheinfeld J. Histology and clinical outcomes in patients with bilateral testicular germ cell tumors: the memorial Sloan Kettering Cancer Center Experience 1950 to 2011. J Urol. 2013;169:2122-2125.

6. Tekin A, Aygun YC, Aki FT, Ozen H. Bilateral germ cell cancer of the testis: a report of 11 patients with a long-term followup. BJU International 2000;85(7):864-868.

7. Kratzik C, Aiginger P, Kuber W, Riccabona M, et al. Risk factors for bilateral testicular germ cell tumors. Cancer 2014:68:916-922.

8. Heidenreich A, Bonfig R, Derschum W, von Vietsch $\mathrm{H}$, Wilbert DM. A conservative approach to bilateral testicular germ cell tumors. J Urol. 2015;153:10-13.
9. American Cancer Society. Cancer Facts and Figures 2013. [en línea]. Dirección URL: <https://www.cancer.org/ research/cancer-facts-statistics/all-cancer-facts-figures/ cancer-facts-figures-2013.html>. [Consulta: octobre de 2008].

10. Klatte T, de Martino M, Arensmeier K, et al. Management and outcome of bilateral testicular germ cell tumors: a 25-year single center experience. Int J Urol 2008;15:821-6.

11. Cortes D. Cryptorchidism: aspects of pathogenesis, histology and treatment. Scand J Urol Nephrol Suppl. 1998;196:1-54.

12. Priebe CJ, Garret R. Testicular calcification in a 4-year-old boy. Pediatrics. 2016;46:785-8.

13. Woodward PJ, Sohaey R, O’Donoghue MJ, Green D. From the archives of the AFIP. Tumors and tumorlike lesions of the testis: Radiologic-pathologic correlation. J Urol. 2013;169:1599.

14. 14.Fossa SD, Chen J, Schonfeld SJ, et al. Risk of contralateral testicular cancer: a population-based study of 29,515 U.S. men. J Natl Cancer Inst 2005;97(14):1056-1066.

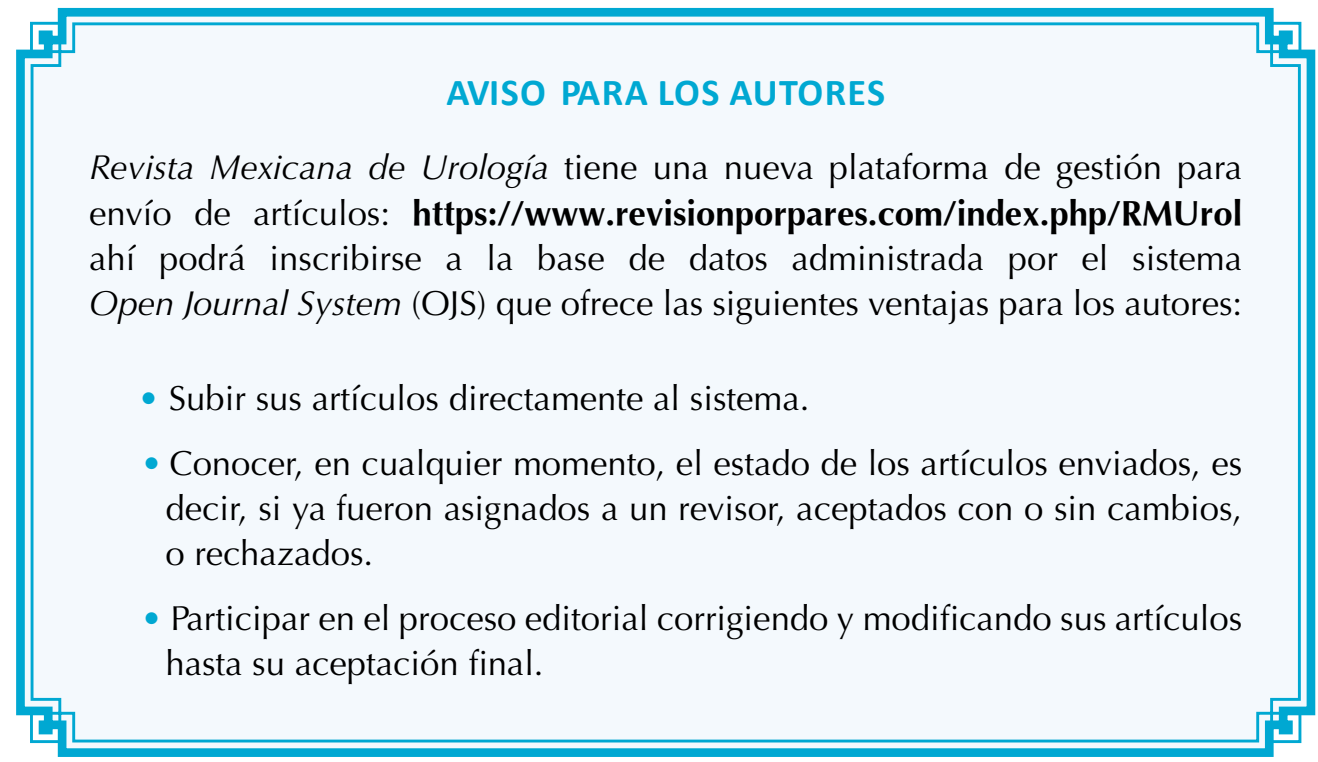

